\title{
APRENDIZAGEM NO ENSINO SUPERIOR: CONTRIBUIÇÕES PARA A PRÁTICA DOCENTE DO PROFESSOR UNIVERSITÁRIO
}

\author{
Letícia de Oliveira Cerqueira ${ }^{1}$; Amali de Angelis Mussi;
}

1. Bolsista FAPESB, Graduando em Letras vernáculas, Universidade Estadual de Feira de Santana, e-mail: leticiaocerqueira@hotmail.com

2. Orientador, Departamento de Educação, Universidade Estadual de Feira de Santana, e-mail: amalimussi@uefs.br

PALAVRAS-CHAVE: Aprendizagem no ensino superior. Docência universitária. Pedagogia Universitária.

\section{INTRODUÇÃO}

Nesse resumo expandido, apresentamos um recorte dos dados obtidos através da pesquisa "Aprendizagem no ensino superior: contribuições para a prática docente do professor universitário". O objetivo da investigação consiste em compreender como os professores do ensino superior caracterizam o processo de aprendizagem dos estudantes universitários, identificando as estratégias que fazem uso para contribuir nesse processo. Para o estudo partimos da premissa de que na atualidade, o ensino superior brasileiro vivencia diferentes desafios, produzidos por processos de mudança de ordem social, econômica e política, ocorridos nas últimas décadas no contexto mundial. Nesse contexto encontram-se também as mudanças históricas produzidas pelas lutas da sociedade a favor da democratização do acesso ao ensino superior, com a conquista de políticas educacionais orientadas para a busca da equidade social, permitindo a inclusão de camadas sociais e culturais plurais, com novas linguagens, necessidades e experiências. Esses processos de mudanças incidem sobre toda sociedade e de forma contundente provocam novas configurações sobre a formação e prática do professor que atua no ensino superior. De acordo com Pozo (2002) a nova cultura de aprendizagem apresenta características próprias que advertem as formas tradicionais de aprendizagem e se compõe por uma cultura de compreensão da análise crítica, da reflexão sobre o que fazemos e acreditamos e não só do consumo, mediado e acelerado pela tecnologia. A discussão proposta agrega-se aos estudos que já vem sendo desenvolvidos pelo Núcleo de Estudo e Pesquisa sobre Pedagogia Universitária (NEPPU) intitulada "Inovação da prática pedagógica de professores do ensino universitário pela pesquisa-ação colaborativa", em uma Universidade Pública do interior da Bahia. Buscamos investigar, frente a esse contexto, como os professores caracterizam a aprendizagem do estudante do ensino superior no cenário atual da Universidade e estratégias pedagógicas utilizadas por eles com vistas garantir que o estudante transforme informações em um conhecimento significativo, com inter-relações e referências seguras do conteúdo.

\section{MATERIAL E MÉTODOS OU METODOLOGIA (ou equivalente)}

Para a coleta de dados, realizamos uma entrevista semiestruturada no qual apresenta questões que envolvem as concepções de aprendizagem dos professores no ensino superior e como os mesmos caracterizam os processos de aprendizagem dos estudantes universitários e dos relatos dos professores durante a reunião do Núcleo de 
Estudos e Pesquisa sobre Pedagogia Universitária (NEPPU). E atividade proposta pelo núcleo de pesquisa "Quando o aluno aprende e quando o aluno não aprende" realizada com os docentes participantes da pesquisa-ação colaborativa sobre a concepção dos professores acerca do que seus alunos aprendem e o que não aprendem. O estudo realizado é de cunho qualitativo, que diz respeito à compreensão dos professores do ensino superior o referente ao processo de aprendizagem dos estudantes universitários e a identificação das estratégias que fazem uso para contribuir nesse processo. Os dados produzidos na pesquisa passaram por um processo de análise de conteúdo do tipo temática (BARDIN, 1997), que se constitui de uma método que possibilita compreender mais profundamente as representações sociais dos professores sobre o objeto estudado permitindo a interpretação dos dados a partir da influencia da linguagem cultural e os seus significados, e ao pesquisador permite que faça uma interpretação pessoal da percepção dos dados. Os três professores (dois atuam UEFS e um na UNEB) analisados fazem parte da pesquisa maior (pesquiça-ação colaborativa), a qual o estudo está articulado.

\section{RESULTADOS E/OU DISCUSSÃO (ou Análise e discussão dos resultados)}

Através de pesquisas e analises constatamos que a prática pedagógica universitária convive, na contemporaneidade, com desafios de diferentes naturezas no qual estabelece uma nova configuração de cultura universitária que reflete na mudança de perfis dos estudantes e dos alunos. Alguns professores distantes do novo contexto não sabem lidar com os novos desafios da sala de aula que os exigem o reconhecimento do seu papel de reconfigurar a realidade já que são indivíduos capazes de transformar sua prática docente. Os participantes da investigação buscam entender o contexto e o papel da universidade para modificar e melhorar sua prática para uma perspectiva de aprendizagem mais condizente com os dias atuais, a aprendizagem em sua visão deve está relacionada ao desenvolvimento do aluno universitário. Além disso, os docentes percebem a importância da utilização e fazem uso das estratégias de ensino e aprendizagem para favorecer o entendimento de determinado conteúdo pelo estudante.

Nossos dados revelaram que é extremamente importante a relação professoraluno baseada por muito dialogo. Um bom relacionamento em sala de aula propicia um aprendizado mais eficiente e passa a existir uma maior interatividade de ambas as partes. Constatou-se, ainda, no presente estudo que para o professor entender o verdadeiro significado da aprendizagem em sua docência precisa compreender as dificuldades e as expectativas do aluno de modo que passe segurança, garantindo o desenvolvimento do aprendizado.

\section{CONSIDERAÇÕES FINAIS (ou Conclusão)}

São importantes os investimentos em pesquisas relacionadas ao processo de aprendizagem dos estudantes universitários e as estratégias utilizadas pelos docentes uma vez que os resultados obtidos buscam construir um conhecimento pedagógico para o campo da docência universitária e na pesquisa-ação colaborativa, oportunizar, na perspectiva do desenvolvimento profissional docente, um processo de ressignificação das concepções e práticas dos professores acerca do processo de aprendizagem do estudante universitário. Sendo assim, a discussões retratadas merecem a nossa atenção!

\section{REFERÊNCIAS}


ANASTASIOU, Lea das Graças C. Desafios da docência universitária em relação a algumas bases teórico-metodológica do ensino de graduação. In: CUNHA, Maria Isabel da; SOARES, Sandra Regina; RIBEIRO, Marinalva Lopes (orgs.). Docência universitária: profissionalização e práticas educativas. Feira de Santana: UEFS Editora, 2009.

BARDIN, Laurence. Análise de conteúdo. Lisboa: Edições 70, 1997.

BEHRENS, Marilda Aparecida. O paradigma da complexividade na formação e no desenvolvimento profissional de professores universitários. Porto Alegre/RS, ano XXX, n.3 (63), p.439-455, set./dez. 2017.

BORTOLETTO, D. Estratégias de aprendizagem e de regulação emocional de estudantes dos cursos de formação de professores. (Dissertação de Mestrado). Universidade Estadual de Campinas, Campinas, SP, 2011;

CUNHA, Maria Isabel da. Inovações pedagógicas na universidade. In: CUNHA, Maria Isabel da; SOARES, Sandra Regina; LOPES, Marinalva Ribeiro (orgs.). Docência universitária: profissionalizaçãoe práticas educativas. Feira de Santana: UEFS Editora, 2009;

GATTI, B. A.; BARRetO, E. S. (coord.) Professores do Brasil: impasses e desafios. Brasilia: UNESCO, 2009.

LENOIR, Yves; LAFOREST, Mario (Dir). La bureaucratisation de la recherche en education et en sciences sociales. Constats, impacts et conséquences. Revue fraçaise de pédagogie, 1998, v. 123, n.123, pp.176-178.

LOUIS, Roland. Inovação pedagógica no ensino superior. In: CUNHA, Maria Isabel da; SOARES, Sandra Regina; RIBEIRO, Marinalva Lopes (orgs.). Docência universitária: profissionalização e práticas educativas. Feira de Santana: UEFS Editora, 2009.

LUCARELLI, Elisa. Prácticas protagônicas e innovación em la universidade. In: CUNHA, M. I. da; SOARES, S. R.; RIBEIRO, M. L. (Orgs.). Docência universitária: profissionalização e práticas educativas. Feira de Santana: UEFS editora, 2009.

MACEDO, Roberto S. Aprendizagem e Formação: aprofundamentos e conexões contemporâneas. Revista Saberes da Faculdade de Ciências Humanas e Sociais (AGES). $1^{a}$ Edição. Número 01, publicado em 30 de julho de 2014. Disponível em: <http://faculdadeages.com.br/saberes/?p=174.> Acesso dez. 2014.

MASETTO, Marcos T.. Cadernos de pedagogia universitária: Docência no ensino superior voltada para a aprendizagem faz a diferença. 12. ed. São Paulo: Puc - São Paulo/mackenzie, 2010. $36 \mathrm{f}$.

MASETTO, Marcos (org.). Inovação no Ensino Superior. São Paulo, Edições: Loyola, 2002. 
MASETTO, Marcos T.. Docência Universitária- Respondendo aula. In: Teodoro a, Vasconcelos ML. Organizadores. Ensinar e aprender no ensino superior. São Paulo( SP): Editora Mackenzie-Cortez; 2003. P. 79-108.

MIRANDA, M. G.; RESENDE, A. C. A. . Sobre a pesquisa-ação na educação e as armadilhas do praticismo. Revista Brasileira de Educação, v. 11, p. 511-518, 2006.

NOGUEIRA, Makeliny Oliveira Gomes. Aprendizagem do aluno adulto: implicações para a prática docente no ensino superior. Curitiba: Ibpex, 2009.

PACHANE, Graziela Giusti. Formação de Professores para a docência universitária no Brasil: Uma introdução histórica. Aprender- Cad. De Filosofia e Psi. da Educação. Vitória da Conquita, ano VII, n.12, p.25-42, 2009.

POZO, Juan Ignacio. Aprendizes e Mestres: a nova cultura da aprendizagem. Porto Alegre: Artmed, 2002

RIBEIRO, Marinalva. L. Formação Pedagógica de Professores da área de Saúde: uma experiência da docência em Didática. In: Sandra Regina Soares; Ilma Fernandes Soares; Mariana Soledade Barreto. (Org.). Formação Pedagógica de Professores da Área de Saüde: uma experiência da Docência em Didática. 1ed.Salvador, Ba: Editora da Universidade do Estado da Bahia EDUNEB, 2013, v. 2, p. 217-248.

TORRE, Saturnino de la e BARRIOS, Oscar. Estrategias didácticas innovadoras. Recursos para la formación y el cambio. Barcelona: OCTAEDRO, 2000.

ZABALZA, M.A. O ensino universitário: seu cenário e seus protagonistas. Porto Alegre: Artmed, 2004.

ZANCHET, B.; CUNHA, M. I. Políticas da educação superior e inovações educativas na sala de aula universitária. In: CUNHA, M. I. (Org.). Reflexões e práticas em pedagogia universitária. Campinas, SP: Papirus, 2007.

ZANCHET, Beatriz Maria Boéssio; GHIGGI, Gomercindo (org.). Práticas inovadoras na aula universitária: possibilidades, desafios e perspectivas. São Luis/ MA: EDUFMA, 2009. 